$$
\text { A } \bigcup_{\text {publications }} \text { Org. Commun.10:2(2017) 79-89 }
$$

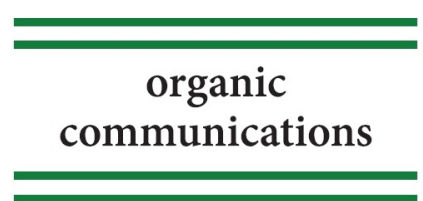

\title{
Asymmetric cyclopropanation of olefins catalyzed by a chiral cobalt(II) porphyrin
}

\author{
Albrecht Berkessel", Erkan Ertürk and Jörg M. Neudörfl \\ Department für Chemie, Universität zu Köln, Greinstrasse 4, 50939 Köln, Germany
}

(Received April 15, 2017; Revised May 25, 2017; Accepted May 26, 2017)

\begin{abstract}
The cobalt(II) complex of the Halterman porphyrin, 5,10,15,20-tetrakis[(1S,4R,5R,8S)-1,2,3,4,5,6,7,8octahydro-1,4:5,8-dimethanoanthracene-9-yl]porphyrinato cobalt(II) [Co(por*)], was synthesized and its structure was identified by X-ray analysis. Up to 80:20 trans:cis diastereomeric ratio and $82 \%$ ee were achieved in the cyclopropanation of styrene with ethyl diazoacetate by using this cobalt(II) porphyrin complex as catalyst. Keywords: Asymmetric catalysis, cyclopropanation, cobalt, porphyrin, ethyl diazoacetate. (C) 2017 ACG Publications. All rights reserved.
\end{abstract}

\section{Introduction}

Catalytic asymmetric cyclopropanation of prochiral olefins via carbene transfer reactions is one of the most frequently used synthetic technique for constructing chiral cyclopropane rings that are encountered in numerous biologically active compounds as well as natural products. ${ }^{1}$ The majority of the methods employ a diazo reagent as the carbene precursor, and a chiral transition metal complex as the catalyst for generating the reactive carbene intermediate. ${ }^{2}$ The catalysts that have been developed for this purpose so far mainly comprise copper(I) ${ }^{3}$ rhodium(II $) /(\mathrm{III}),{ }^{4}$ ruthenium(II) ${ }^{5}$ and cobalt (II)/(III) $)^{6,7}$ complexes. ${ }^{2 c, d}$

Since the work of Callot and Piechocki in 1980 in which a metal porphyrin complex, i.e. rhodium(III) tetraphenylporphyrin iodide, was for the first time reported to be capable of catalyzing cyclopropanation of alkenes with ethyl diazoacetate (EDA), ${ }^{8}$ metal porphyrins have been shown to feature high catalytic turnover numbers (TONs) in alkene cyclopropanation using diazo reagents, due to their robustness. O'Malley and Kodadek then developed rhodium(III) complexes of "chiral wall" and "chiral fortress" porphyrins as the first enantioselective metal-porphyrin catalysts for cyclopropanation, and modest cis/trans diastereoselectivities and enantioselectivities were achieved. ${ }^{9}$ Among the metal porphyrin complexes, such as iridium(III), ${ }^{10}$ osmium(III), ${ }^{11}$ iron(II $)^{12,13}$ ruthenium(II) ${ }^{14}$ and cobalt(II) ${ }^{15,16}$ porphyrin complexes, ruthenium(II) and iron(III) prophyrins have appeared to possess higher catalytic activities in cyclopropanation of olefins with diazo reagents. Thus, up to 7500 and 10000 TONs were observed for $\mathrm{Ru}(\mathrm{II})^{14 \mathrm{~h}}$ and $\mathrm{Fe}(\mathrm{III})^{13 \mathrm{c}}$ porphyrins, respectively.

In spite of the fact that the stoichiometric condensation reaction of cobalt(II) porphyrin complexes with ethyl diazoacetates (EDA) was already disclosed by Johnson and co-workers in $1975,{ }^{15 a}$ only recent years have witnessed significant impact of cobalt(II) porphyrins to the

\footnotetext{
* Corresponding authors: E-Mail: berkessel@uni-koeln.de; Tel: +49 (221) 470 3283; Fax: +49 (221) 4705102
} 
cyclopropanation of olefins with diazo reagents. ${ }^{16-23}$ The EPR, ESI-MS as well as DFT studies revealed that the cobalt(II)-porphyrin-mediated cyclopropanation of olefins with diazoesters proceeds via the formation of the Fischer-type radical carbene II followed by a stepwise radical addition of an olefin (1) and cyclization cascade toward the corresponding cyclopropanes 3 and $\mathbf{4}$ (Scheme 1). ${ }^{17,18}$ The "terminal radical carbene species" II and the "bridging carbene species" III were proposed to exist as redox isomers and in dynamic equilibrium with each other, although the latter was determined to be thermodynamically somewhat more stable according to DFT calculations. ${ }^{18}$ While the dynamic equilibrium between the species II and III is expected to prevent the formation of dimerization byproducts (e.g. diethyl fumarate and diethyl maleate in case of EDA) during olefin cyclopropanation, the existence of radical carbene moiety bound to $\mathrm{d}^{6} \mathrm{Co}^{\mathrm{III}}$ center of the species II accounts for its more nucleophilic character, i.e. radical reactivity that is unusual for carbenes bound to other metal porphyrin complexes. ${ }^{17,10}$ The nucleophilic character of the carbene radicals II enables cobalt(II) porphyrins to catalyze also the cyclopropanation of electron-deficient olefins such as methyl acrylate. ${ }^{16 e}$ Zhang and co-workers developed $D_{2}$-symmetric chiral porphyrin ligands bearing secondary amide functionality and their cobalt(II) complexes as cyclopropanation catalysts. ${ }^{16 \mathrm{c}, 16 \mathrm{e} 16 \mathrm{~h}, 16 \mathrm{i}}$ Cobalt(II) porphyrins with amide functionality showed higher reactivities and diastereo- and enantioselectivities than those without amide functionality such as cobalt(II) tetraphenylporphyrin. This observation was attributed to the formation of a hydrogen bond between the carbonyl oxygen of the carbene moiety and the N-H hydrogen of the amide functionality. It should also be noted that the addition of 0.50 equivalents of 4-dimethylaminopyridine (DMAP) to the catalytic system for cyclopropanation, described by Zhang and co-workers, was found to be crucial for achieving high activity and stereoselectivity. This was ascribed to the so-called trans effect of DMAP. Thus, cobalt(II) complexes of Zhangs' chiral porphyrins having amide functionality have emerged as general and highly diastereoand enantioselective catalysts for the cyclopropanation of olefins with diazo reagents. ${ }^{19-23}$ All these developments, as well as our continuing interest in metal-porphyrins in asymmetric catalysis, ${ }^{14 \mathrm{c}, 14 \mathrm{~h}, 24}$ have prompted us to disclose our recent work on the synthesis of the cobalt(II) complex of the Halterman prophyrin, and its catalytic performance in the cyclopropanation of olefins with diazo esters.
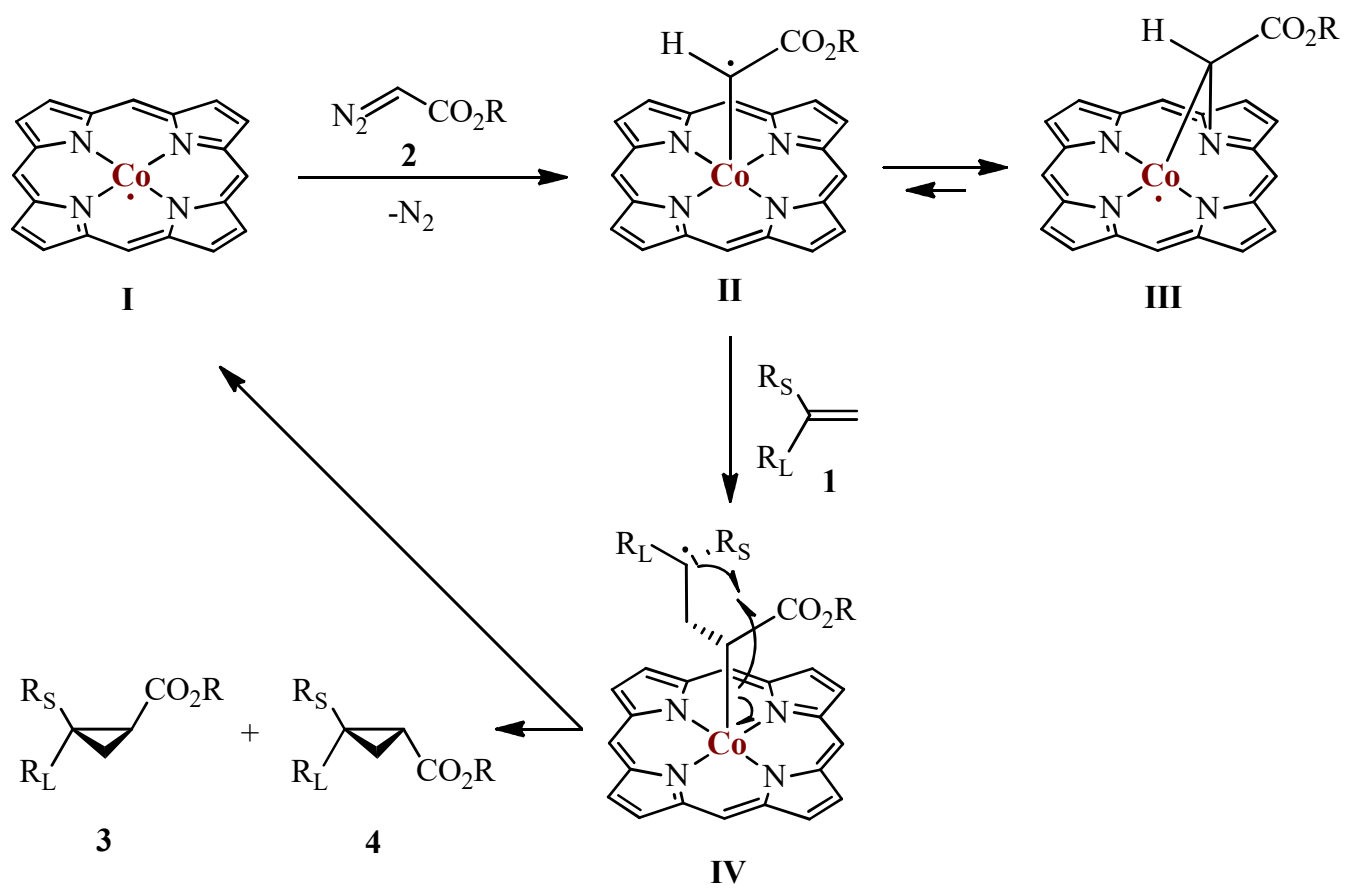

Scheme 1. Stepwise radical mechanism for the Co (por)-catalyzed cyclopropanation of olefins. 


\section{Experimental}

5,10,15,20-Tetrakismesitylporphyrin (5) was prepared from mesitaldehyde and pyrrole under Lindsey conditions. ${ }^{25}$ Cobalt(II) tetramesitylporphyrin (CoTMP, 6) was synthesized from the reaction of the porphyrin ligand 5 with excessive $\mathrm{Co}(\mathrm{OAc})_{2} \cdot 4 \mathrm{H}_{2} \mathrm{O}$ in boiling mixture of $\mathrm{CHCl}_{3}-\mathrm{MeOH}$ and it was purified via column chromatography (aluminum oxide, neutral, hexane/ $\mathrm{CHCl}_{3}$, gradient elution from 10:0.2 to $10: 1){ }^{26}$ The chiral Halterman porphyrin ligand (7) was prepared according to the literature. ${ }^{27}$ Ethyl diazoacetate (EDA) was purchased from Aldrich and used as received. tert-Butyl diazoacetate $\left({ }^{t} \mathrm{BDA}\right)$ was prepared from tert-butyl glycinate hydrochloride according to the literature. ${ }^{28}$ All reactions were carried out in oven-dried Schlenk tubes with magnetic stirring under a positive pressure of argon. Toluene and THF were freshly distilled from sodium/benzophenone prior to use under an argon atmosphere. Dichloromethane (DCM) was dried by distillation over calcium hydride under argon atmosphere. Dimethyl formamide (DMF) was dried over calcium hydride and distilled under reduced pressure under argon. ${ }^{1} \mathrm{H}$ and ${ }^{13} \mathrm{C}$ NMR spectra were recorded on a Bruker AC 300 instrument. The IR measurements were performed on a Perkin-Elmer Paragon 1000 spectrometer. UV-Vis spectra were obtained on a Beckman Coulter DU 800 spectrometer. EI mass spectra were provided on a Finnigan MAT 900. Optical rotations were measured on a Perkin-Elmer polarimeter 343 plus. The absolute configurations of the products were determined by comparison of their optical rotations with literature data, as well as by chiral GC or HPLC analysis.

2.1. Synthesis of 5,10,15,20-tetrakis[(1S,4R,5R,8S)-1,2,3,4,5,6,7,8-octahydro-1,4:5,8dimetha-noanthracene-9-yl]porphyrinato cobalt(II) (8): The enantiomerically pure porphyrin ligand 7 (114 mg, $0.1 \mathrm{mmol}, 1.00$ equiv) was placed in an oven-dried round-bottomed two-neck flask equipped with a reflux condenser. The flask was evacuated for $15 \mathrm{~min}$ and back-filled with argon. After addition of $30 \mathrm{~mL}$ of dry $\mathrm{CHCl}_{3}$ and $10 \mathrm{~mL}$ of dry DMF by means of gas-tight syringes, the resulting solution was heated to $65^{\circ} \mathrm{C}$ (oil bath temperature) under Ar whereupon the reaction mixture became homogenous. $\mathrm{Co}(\mathrm{OAc})_{2} \cdot 4 \mathrm{H}_{2} \mathrm{O}(150 \mathrm{mg}, 0.6 \mathrm{mmol}, 6.00$ equiv) was added in one portion and the resulting reaction mixture was stirred at $65^{\circ} \mathrm{C}$ for $12 \mathrm{~h}$ under Ar. After cooling to rt, the organic phase was washed several times with water $(3 \times 50 \mathrm{~mL})$ in a separatory funnel, and dried over $\mathrm{Na}_{2} \mathrm{SO}_{4}$. All volatile components of the solution were removed under reduced pressure by rotary evaporation. The crude product was then purified by dry column chromatography on aluminum oxide (neutral, Fluka, Brockmann activity I) using $n$-hexane-chloroform (10:0.1) as eluent. $80 \mathrm{mg}$ ( $67 \mu \mathrm{mol}, 67 \%)$ of the chiral cobalt(II) porphyrin complex $\mathbf{8}$ were obtained as brick red powder. Remaining porphyrin ligand was also recovered in this way. Crystals suitable for X-ray analysis were grown from dichlormethane-acetonitrile mixture. $\mathrm{Mp}>250{ }^{\circ} \mathrm{C}, R_{f}=0.26$ (aluminum oxide, neutral; $n$-hexanechloroform, 10:0.1). UV-VIS: $\lambda_{(\max )}=413 \mathrm{~nm}\left(\mathrm{CHCl}_{3}\right)$. FT-IR $(\mathrm{CsBr}): v\left(\mathrm{~cm}^{-1}\right)=2964[\mathrm{~s},(\mathrm{C}-\mathrm{H})$ alkyl], 2921 [w, (C-H) alkyl], 2869 [m, v(C-H) alkyl], 1473 [w, (C-H) alkyl], 1297,1104 [both m], 1009, 950, 864 [all w], 801 [m, (C-H) aryl], 756, 709 [both w] $\mathrm{cm}^{-1}$. HR-MS (EI): $\mathrm{m} / z[\mathrm{M}]^{+}$calcd for $\mathrm{C}_{84} \mathrm{H}_{76} \mathrm{~N}_{4} \mathrm{Co}$ : 1199.5402; found: 1199.5400. EA: Anal. Calcd. for $\mathrm{C}_{84} \mathrm{H}_{76} \mathrm{~N}_{4} \mathrm{Co}: \mathrm{C}, 84.04 ; \mathrm{H}, 6.38 ; \mathrm{N}$, 4.67. Found: C, 82.79; H, 6.57; N: 4.62 .

X-ray crystal structure analysis of $(\boldsymbol{8}): \mathrm{C}_{84} \mathrm{H}_{76} \mathrm{CoN}_{4}, \mathrm{M}=1200.46$, brick red crystals, $0.05 \times 0.1 \times 0.1$ $\mathrm{mm}$, monoclinic, $\mathrm{a}=23.018(5), \mathrm{b}=17.890(5), \mathrm{c}=19.247(5) \AA, \beta=126.57(5)^{\mathrm{o}}, \mathrm{V}=6366(3) \AA^{3}, \mathrm{~T}=$ $100(2) \mathrm{K}$, space group $\mathrm{C} 2, \mathrm{Z}=4, \mathrm{~d}_{\text {calcd }}=1.253 \mathrm{~g} / \mathrm{cm}^{3}, \mu=0.321 \mathrm{~mm}^{-1}$. A total of 5255 reflections were measured. Final residuals were R1 $=0.0533$ and $w R 2=0.0978$ (for 3755 observed reflections with $\mathrm{I}>$ $2 \sigma(\mathrm{I}), 802$ parameters) with GOF 1.015 and largest residual peak $0.264 \mathrm{e} \AA^{-3}$ and hole $-0.317 \mathrm{e} \AA^{-3}$.

All data were collected on an Nonius Kappa CCD diffractometer $\left(2 \Theta_{\max }=50^{\circ}, \mathrm{Mo}_{\mathrm{K} \alpha}\right.$ radiation $(\lambda=0.71073 \AA)$, graphite monochromator, $\varphi / \omega$ - scans). The structure was solved using direct methods (SIR-97, Altomare, A.; Cascarano, G.; Giacovazzo, C.; Guagliardi, A.; Moliterni, A.G.G.; Burla, M.C.; Polidori, G.; Camalli, M.; Spagna, R.), followed by full-matrix least squares refinement with anisotropic thermal parameters for $\mathrm{C}, \mathrm{N}, \mathrm{O}$ and $\mathrm{F}$ and fixed parameters for $\mathrm{H}$ (SHELXL-2014, Sheldrick, G. M.: Program for the Refinement of Crystal Structures. University of 
Chiral co-porphyrin for catalytic asymmetric cyclopropanation

Göttingen, Germany 2015). The crystallographic data (excluding structure factors) have been deposited with the Cambridge Crystallographic Data Centre as supplementary publication no. CCDC1535476. Copies of the data can be obtained free of charge on application to CCDC, 12 Union Road, Cambridge CB21EZ, UK (fax: (+ 44)1223-336-033; e-mail: deposit@ccdc.cam.ac.uk).

\subsection{General procedure for the cobalt(II) porphyrin-catalyzed cyclopropanation:}

A catalytic amount of the cobalt(II) porphyrin complex 6 or 8 (see Table 1) was placed in an ovendried Schlenk tube and then the tube was capped with a glass stopper. The tube was evacuated for 15 min and back-filled with argon. The glass stopper was replaced with a rubber septum under positive pressure of argon. After addition of absolute solvent, olefin (1.00 equiv) was added which was succeeded by the addition of an additive, if necessary. The homogenous mixture was stirred for ca. 5 $\mathrm{min}$ at room temperature and then 1.20 equiv of ethyl diazoacetate (2a) or tert-butyl diazoacetate (2b) were added via syringe at once whereupon gas evolution was observed. After stirring the reaction mixture for a while at a certain temperature as indicated in Table 1 or Table 2, the yield of the reaction was determined by $\mathrm{GC}$ analysis or isolating the products by column chromatography.

2.3. trans- and cis-Ethyl 2-phenylcyclopropanecarboxylate (3a and 4a): GC analysis (chiral): WCOT-FS, CP Chirasil-Dex CB, $25 \mathrm{~m}, 0.25 \mathrm{~mm}$ ID; inlet: $250{ }^{\circ} \mathrm{C}$ (split modus); det.: $250{ }^{\circ} \mathrm{C}$ (FID); $\mathrm{He}, 1.2 \mathrm{~mL} \cdot \mathrm{min}^{-1}$ (constant flow modus); oven: $80^{\circ} \mathrm{C}, 5{ }^{\circ} \mathrm{C} \cdot \min ^{-1}, 115^{\circ} \mathrm{C}(40 \mathrm{~min}), 4{ }^{\circ} \mathrm{C} \cdot \mathrm{min}^{-1}, 120$ ${ }^{\circ} \mathrm{C}(5 \mathrm{~min}), 1{ }^{\circ} \mathrm{C} \cdot \mathrm{min}^{-1}, 160{ }^{\circ} \mathrm{C}(3 \mathrm{~min}) \cdot t_{\mathrm{R}}=3.5 \mathrm{~min}$ (styrene), $t_{\mathrm{R}}=11.0 \mathrm{~min}$ (1,2-dibromobenzene as the internal standard), $t_{\mathrm{R}}=30.2 \mathrm{~min}\left(\right.$ ent-4a), $t_{\mathrm{R}}=32.6 \mathrm{~min}(\mathbf{4 a}), t_{\mathrm{R}}=34.4 \mathrm{~min}(\mathbf{3 a}), t_{\mathrm{R}}=35.8 \mathrm{~min}($ ent-3a).

2.4. trans-and cis-tert-Butyl 2-phenylcyclopropanecarboxylate ( $3 \boldsymbol{b}$ and $4 \boldsymbol{b})$ : $\mathrm{GC}$ analysis (chiral): WCOT-FS, CP Chirasil-Dex CB, $25 \mathrm{~m}, 0.25 \mathrm{~mm}$ ID; inlet: $250{ }^{\circ} \mathrm{C}$ (split modus); det.: $250{ }^{\circ} \mathrm{C}$ (FID); $\mathrm{N}_{2}, 12$ psi column head pressure (constant pressure modus); oven: $80^{\circ} \mathrm{C}, 5{ }^{\circ} \mathrm{C} \cdot \mathrm{min}^{-1}, 115{ }^{\circ} \mathrm{C}$ $(40 \mathrm{~min}), 4{ }^{\circ} \mathrm{C} \cdot \min ^{-1}, 130{ }^{\circ} \mathrm{C}(15 \mathrm{~min}), 15^{\circ} \mathrm{C} \cdot \mathrm{min}^{-1}, 160{ }^{\circ} \mathrm{C}(3 \mathrm{~min}) . t_{\mathrm{R}}=51.8 \mathrm{~min}(4 \mathbf{b}), t_{\mathrm{R}}=52.3 \mathrm{~min}$ $\left(\right.$ ent-4b), $t_{\mathrm{R}}=59.9 \min ($ ent $-\mathbf{3 b}), t_{\mathrm{R}}=60.3 \min (\mathbf{3 b})$.

HPLC analysis (chiral): Chiralcel OD-H; eluent: $n$-hexane $(100 \%)$, flow rate: $0.7 \mathrm{~mL} \cdot \mathrm{min}^{-1}$, pressure: 23 bar; detection: $254 \mathrm{~nm}(\mathrm{UV}) . t_{\mathrm{R}}=16.6 \mathrm{~min}(\mathbf{3 b}), t_{\mathrm{R}}=20.0 \mathrm{~min}$ (ent-3b). No separation for the enantiomers $\mathbf{4 b}$ and ent-4b was observed on this chiral column.

2.5. Ethyl 2,2-diphenylcyclopropanecarboxylate (3c ):HPLC analysis (chiral): Chiralpak OJ; eluent: $n$-hexane $/{ }^{/} \mathrm{PrOH}, 85: 15$; flow rate: $1.0 \mathrm{~mL} \cdot \mathrm{min}^{-1}$, pressure: 27 bar; detection: $254 \mathrm{~nm}$ (UV). $t_{\mathrm{R}}=18.6 \min ($ ent $-\mathbf{3 c}), t_{\mathrm{R}}=28.0 \mathrm{~min}(\mathbf{3 c})$.

\section{Results and Discussion}

The cobalt(II) porphyrin 6 (TMPCo) was prepared according to the literature. ${ }^{26}$ The chiral cobalt(II) porphyrin 8 (Co(por*)) was obtained by reacting the enantiomerically pure porphyrin ligand 7 with an excess of cobalt(II) acetate tetrahydrate $\left(\mathrm{Co}(\mathrm{OAc})_{2} \cdot 4 \mathrm{H}_{2} \mathrm{O}\right)$ in $\mathrm{CHCl}_{3}$-DMF solvent mixture (3:1) at $65{ }^{\circ} \mathrm{C}$ under Ar (Figure 1). The structure of the new cobalt complex of the Halterman porphyrin (8) was well identified by X-ray analysis. It should be noted that the cobalt complex $\mathbf{8}$ could not be formed when the Halterman porphyrin (7) was interacted with some selected cobalt sources, such as $\mathrm{CoCl}_{2}, \mathrm{Co}(\mathrm{OAc})_{2}$, in boiling DMF which is known to be the usual technique for the synthesis of cobalt(II) porphyrin complexes. Even in boiling DMF, the Halterman porphyrin (7) was found to be practically insoluble, which possibly hampered the cobalt insertion in DMF. 


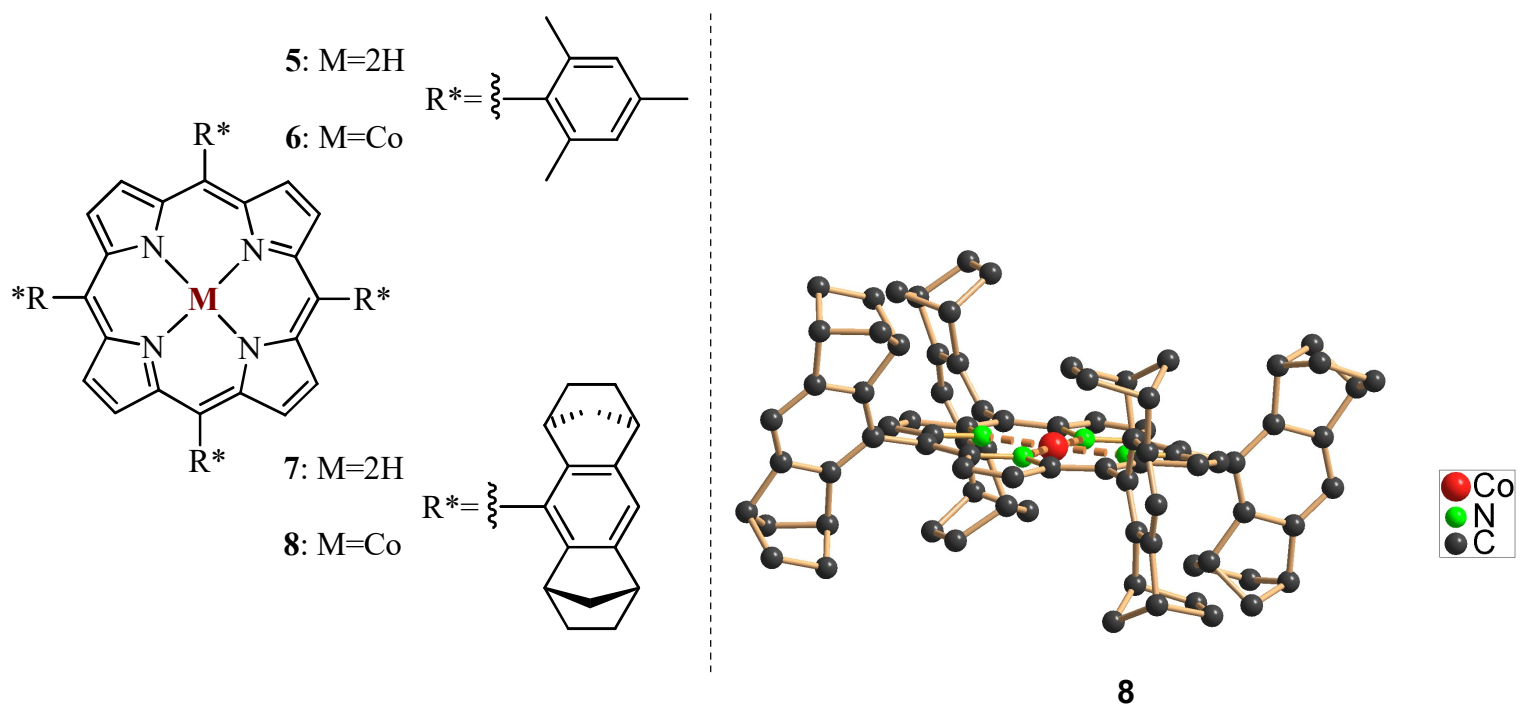

Figure 1. Cobalt(II) porphyrin complexes 6 [Co(TMP)] and 8 [Co(por*)] (left). The structure of $\mathrm{Co}$ (por*) (right). Hydrogen atoms were omitted for clarity.

We then revisited the catalytic cyclopropanation of styrene (1a) with EDA (2a) and ${ }^{t} \mathrm{BDA}(\mathbf{2} \mathbf{b})$ in the presence of $\mathbf{6}$ (Table 1). Co(TMP) (6) was chosen as the model complex to find out the optimum reaction conditions because of its very close similarity to the our $\mathrm{Co}($ por*) $(\mathbf{8})$ in terms of its steric and electronic features as well as considering its ready availability. The results are summarized in Table 1 . A vigorous reaction between 1a and 2a in toluene at $\mathrm{rt}$ was observed when $2 \mathrm{~mol} \%$ of $\mathbf{6}$ was employed (Table 1, entry 1). The conversion was almost quantitative after 20 min. Then, the amount of 6 was reduced on $1.5 \mathrm{~mol} \%, 1 \mathrm{~mol} \%$, and $0.5 \mathrm{~mol} \%$, successively (Table 1, entries 2, 3, and 4). Under these conditions, the reaction between 1a and $\mathbf{2 a}$ also smoothly took place, giving the same diastereomeric ratio (trans/cis, 70:30). However, $1 \mathrm{~mol} \%$ of the Co(TMP) amount was determined to be optimal with regard to the reaction time (Table 1, entry 3 ). When the solvent was changed to THF, the reaction took more than one day, and did not go to completion even at $60{ }^{\circ} \mathrm{C}$ (Table 1, entry 5). Cobalt(III) tetramesitylporphyrin bromide $\left(\mathrm{Co}{ }^{\mathrm{III}}(\mathrm{TMP}) \mathrm{Br}\right)$ that was generated in situ by treating 6 with $\mathrm{Br}_{2}(0.5$ equiv. relative to 6) before adding styrene and EDA to the reaction mixture was also tested as potential catalyst for cyclopropanation of styrene (1a) with EDA (2a). However, no conversion was detected in this case (Table 1, entry 6). ${ }^{t}$ BDA (2b) was then used as carbene source. While the reaction of styrene (1a) with EDA (2a) in the presence of $1 \mathrm{~mol} \%$ of $\mathrm{Co}$ (TMP) was proceeding very well giving the desired cyclopropanes in high yield, the reaction mixture of styrene (1a) and ${ }^{t}$ BDA (2b) had to be heated up to $80{ }^{\circ} \mathrm{C}$ affording the corresponding cyclopropane products $\mathbf{3 b}$ and $\mathbf{4 b}$ in reasonable yield (85\%) under the same conditions (Table 1, entries 3, 7, and 8). Changing the diazo ester from EDA to ${ }^{t}$ BDA afforded higher diastereoselectivity, 70:30 vs. 90:10 trans:cis ratio, respectively, as expected (Table 1, entry 3 and 8). The effect of co-ligands was also investigated expecting to observe any coligand acceleration in the cyclopropanation of styrene (1a) with ${ }^{t} \mathrm{BDA}(\mathbf{2 b})$ because of the somewhat slower reaction between $\mathbf{1 a}$ and $\mathbf{2 b}$. For this purpose, 4-(dimethylamino)pyridine (DMAP) and $\mathrm{N}$ methyl imidazole (NMI) were tested as coordinating co-ligand. However, in contrast to our expectations, an inhibition in the presence of NMI and a deceleration in the presence of DMAP of were observed (Table 1, entries 8,9, and 10). After these screenings, the optimum conditions for the cyclopropanation of styrene were determined by using EDA and ${ }^{t}$ BDA (Table 1, entries 3 and 8 respectively). Cyclopropanation of 1-octene and 1,2-dihydronaphthalene was also tried, by using 1 mol\% 6 and EDA in toluene. However, no conversion was detected in both cases. These "negative" results are in line with the reactivity profiles for cobalt porphyrin-based radical carbenes in cyclopropanation observed previously: There has been no report on the cyclopropanation of aliphatic olefins and 1,2-dihydronaphthalene with EDA or ${ }^{t} \mathrm{BDA}$, in the presence of $\mathrm{Co}(\mathrm{II})$ porphyrins. 
Nonetheless, Zhang et al. demonstrated that 1-hexene could be cyclopropanated with $\alpha$ nitrodiazoacetates, a special carbene source, in modest yield (43\%) by using a bifunctional Co(II) porphyrin. ${ }^{20}$ The inefficiency of $\mathrm{Co}$ (TMP) (6) in the cyclopropanation of 1-octene might be attributed to the stability of the cobalt porphyrin carbenes induced by the equilibrium between the "radical carbene" II and the "bridging carbene" III redox isomers. On the other hand, it can be expected that steric factors could prevent the cyclopropanation of 1,2-dihydronaphthalene. It is worthy to note that no dimerization by-products, i.e. maleate or fumarate esters, were detected during cyclopropanation of styrene with EDA and ${ }^{t} \mathrm{BDA}$.

Table 1. Cyclopropanation of styrene (1a) with diazo esters $\mathbf{2 a}$ and $\mathbf{2 b}$ catalyzed by $\operatorname{Co}(\mathrm{TMP})(\mathbf{6}){ }^{a}$

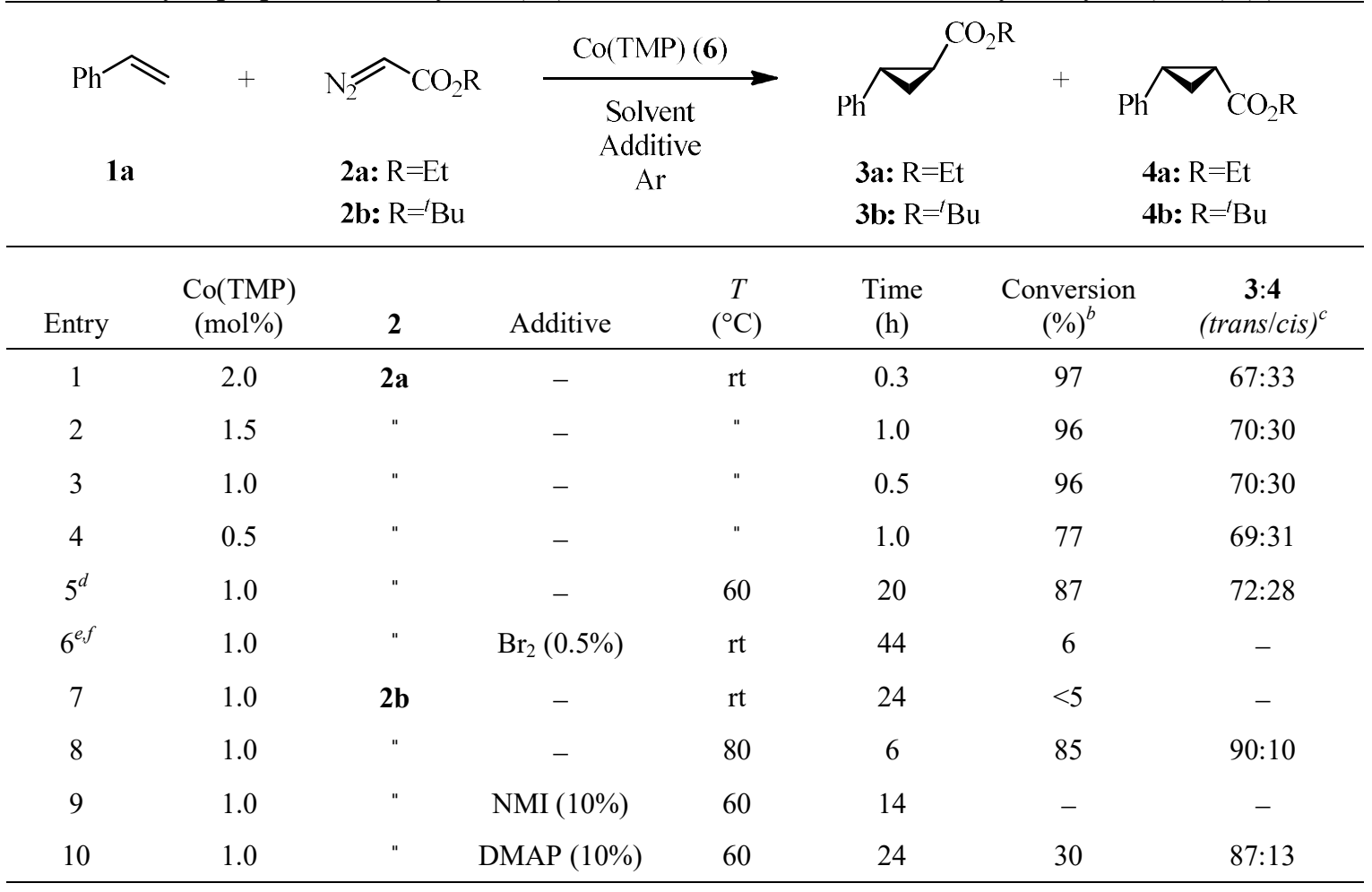

${ }^{a}$ Typical reaction conditions: To the solution of styrene $(315 \mu \mathrm{mol}, 1.00$ equiv) and $\mathbf{6}$ in dry toluene $(0.4 \mathrm{~mL})$ under Ar was added the diazo ester $\mathbf{2 a}$ or $\mathbf{2 b}$ via syringe at once. ${ }^{b}$ Conversions of styrene (1a) to the product were determined by GC using 1,2-dibromobenzene as internal standard. ${ }^{c}$ trans/cis ratios were determined by GC. ${ }^{d}$ THF was used as the solvent. ${ }^{e}$ DCM was used as the solvent. ${ }^{f}$ This reaction was also run in the presence of $2 \mathrm{~mol} \% \mathrm{MeOH}$ to test $\mathrm{Co}^{\text {III }}(\mathrm{TMP})(\mathrm{MeOH})_{2} \mathrm{Br}$ as potential catalyst. However, no conversion was observed.

The asymmetric cyclopropanation using $\operatorname{Co}($ por*) (8) was investigated next, under the optimized conditions determined with Co(TMP) (Table 2). A 76:24 trans/cis diastereomeric ratio and $77 \%$ ee (trans) and 22\% ee (cis) for the cyclopropanation of styrene (1a) with EDA (2a) were observed (Table 2, entry 1). While the presence of NMI as co-ligand delivered significantly higher diastereomeric ratio in favor of the trans-diastereomer, and higher ee for the cis-diastereomer, but lower ee for the trans-diastereomer, the presence of $\mathrm{MeOH}$ as co-ligand afforded somewhat higher diastereomeric ratio in favor of trans-diastereomer and higher ee for trans-diastereomer but somewhat lower ee for cis-diastereomer (Table 2, entries 2 and 3) compared to no co-ligand (Table 2, entry 1). Thus, 87:13 trans/cis diastereomeric ratio, $65 \%$ ee for trans- (3a) and 43\% ee for cis- diastereomer (4a) were observed with $95 \%$ total product yield in the presence of NMI (10 mol\%). In the presence of $\mathrm{MeOH}$ (10 mol\%), 80:20 trans/cis diastereomeric ratio, 82\% ee for trans- (3a) and 19\% ee for cisdiastereomer (4a) were attained with $96 \%$ total product yield within $1 \mathrm{~h}$ at room temperature. A 82:18 trans/cis diastereomeric ratio and 60\% ee for trans-diastereomer (3b) and 32\% ee for cis-diastereomer 
(4b) were determined for the cyclopropanation products of styrene (1a) with ${ }^{t} \mathrm{BDA}$ (Table 2, entry 4). The diastereoselectivity and the enantioselectivity were slightly affected by the presence of $\mathrm{MeOH}$ (Table 2, entry 5). It is worthy to note that $\mathrm{Co}$ (TMP) furnished higher diastereoselectivity than $\mathrm{Co}$ (por*) in the cyclopropanation of styrene with ${ }^{t} \mathrm{BDA}, 90: 10$ and 82:18 trans/cis diastereomeric ratio, respectively (Table 1 , entry 8 and Table 2, entry 4). The cyclopropanation of 1,1diphenylethylene (1b) with EDA (2a) catalyzed by $\mathrm{Co}\left(\right.$ por* $\left.^{*}\right)(\mathbf{8})$ gave the corresponding cyclopropane $3 \mathbf{c}$ with moderate yield (62\%) and enantiomeric excess (50\% ee) (Table 2, entry 6). Previously, Ru(II) and $\mathrm{Fe}$ (III) complexes of the $D_{4}$-symmetric Halterman porphyrin were shown to catalyze asymmetric cyclopropanation of styrene derivatives with diazo esters. ${ }^{14-c, h, 13 b}$ While enantiomeric excesses that are herein presented with its $\mathrm{Co}$ (II) complex are comparable with those reported with its $\mathrm{Fe}(\mathrm{III})$ complex, they are lower than those achieved with its $\mathrm{Ru}(\mathrm{II})$ complex.

Table 2. Asymmetric cyclopropanation of olefins with diazo esters catalyzed by $\operatorname{Co}\left(\right.$ por* $\left.^{*}\right)(\mathbf{8}){ }^{a}$<smiles>[R]C([R])=C</smiles>

1a: $\mathrm{R}^{1}=\mathrm{Ph}, \mathrm{R}^{2}=\mathrm{H}$

1b: $\mathrm{R}^{1}=\mathrm{R}^{2}=\mathrm{Ph}$<smiles>[R]OC(=O)C=N</smiles>

2a: $\mathrm{R}=\mathrm{Et}$

2b: $\mathrm{R}={ }^{\prime} \mathrm{Bu}$

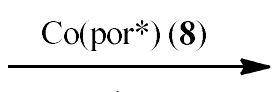

Solvent Additive $\mathrm{Ar}$

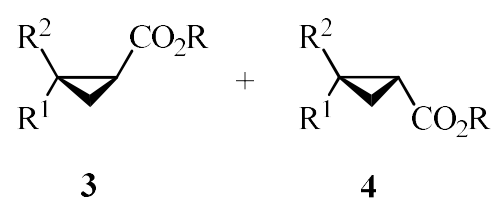

3a, 4a: $\mathrm{R}=\mathrm{Et}, \mathrm{R}^{1}=\mathrm{Ph}, \mathrm{R}^{2}=\mathrm{H}$

3b, $\mathbf{4 b}: \mathrm{R}={ }^{\prime} \mathrm{Bu}, \mathrm{R}^{1}=\mathrm{Ph}, \mathrm{R}^{2}=\mathrm{H}$

3c: $\mathrm{R}=\mathrm{Et}, \mathrm{R}^{1}=\mathrm{R}^{2}=\mathrm{Ph}$

\begin{tabular}{cccccccccc}
\hline Entry & $\mathbf{1}$ & $\mathbf{2}$ & Additive $^{b}$ & $\begin{array}{c}T \\
\left({ }^{\circ} \mathrm{C}\right)\end{array}$ & $\begin{array}{c}\text { Time } \\
(\mathrm{h})\end{array}$ & $\begin{array}{c}\text { Yield } \\
(\%)^{c}\end{array}$ & $\begin{array}{c}\mathbf{3}: \mathbf{4} \\
\left(\text { trans/cis }^{2}\right.\end{array}$ & $\begin{array}{c}\text { ee trans } \\
(\%)\end{array}$ & $\begin{array}{c}\text { ee cis } \\
(\%)\end{array}$ \\
\hline 1 & $\mathbf{1 a}$ & $\mathbf{2 a}$ & - & $\mathrm{rt}$ & 1 & 88 & $76: 24^{d}$ & $77(1 S, 2 S)^{e}$ & $22(1 R, 2 S)^{e}$ \\
2 & $\mathbf{1 a}$ & $\mathbf{2 a}$ & $\mathrm{NMI}$ & $\mathrm{rt}$ & 1 & 95 & $87: 13$ & $65(1 S, 2 S)$ & $43(1 R, 2 S)$ \\
3 & $\mathbf{1 a}$ & $\mathbf{2 a}$ & $\mathrm{MeOH}$ & $\mathrm{rt}$ & 1 & 96 & $80: 20$ & $82(1 S, 2 S)$ & $19(1 R, 2 S)$ \\
$4^{f}$ & $\mathbf{1 a}$ & $\mathbf{2 b}$ & - & 70 & 6 & 85 & $82: 18^{g}$ & $60(1 S, 2 S)^{h, i}$ & $32^{h}$ \\
5 & $\mathbf{1 a}$ & $\mathbf{2 b}$ & $\mathrm{MeOH}$ & 70 & 3 & 87 & $83: 17$ & $61(1 S, 2 S)$ & 32 \\
6 & $\mathbf{1 b}$ & $\mathbf{2 a}$ & $\mathrm{MeOH}$ & $\mathrm{rt}$ & 5 & 62 & - & \multicolumn{2}{c}{$50(S)^{j, i}$} \\
\hline
\end{tabular}

${ }^{a}$ Typical reaction conditions: To the solution of olefin (315 $\mu \mathrm{mol}, 1.00$ equiv) and $8(1.0 \mathrm{~mol} \%)$ in dry toluene $(0.4 \mathrm{~mL})$ under Ar was added the diazo ester $\mathbf{2 a}$ or $\mathbf{2 b}$ (1.20 equiv) via syringe at once. ${ }^{b} 10 \mathrm{~mol} \%$ of an additive was employed. ${ }^{c}$ Isolated yield after column chromatography. ${ }^{d}$ Determined by GC analysis by comparison with authentic sample and ${ }^{1} \mathrm{H}$ NMR spectroscopy. ${ }^{e}$ Determined by GC analysis by using chiral column (WCOT-FS, CP Chirasil -Dex CB). The absolute configuration was determined by comparison with authentic sample. ${ }^{f} 1.5$ mol $\%$ of $\mathbf{8}$ was used. ${ }^{g}$ Determined by ${ }^{1} \mathrm{H}$ NMR spectroscopy. ${ }^{6 \mathrm{~d} h}$ Determined by GC analysis by using chiral column (WCOT-FS, CP Chirasil -Dex CB). ${ }^{\mathrm{i}}$ The absolute configuration was determined by comparison of the sign of optical rotation using HPLC (Chiralcel OD-H) equipped with Chiralyser. ${ }^{j}$ Enantiomeric excess was determined by HPLC analysis using chiral column (Chiralcel OJ).

\section{Conclusion}

In summary, the cobalt(II) complex (Co(por*)) of the Halterman porphyrin was synthesized and its single crystal X-ray analysis was provided. Diastereo- and enantioselective cyclopropanation of olefins with EDA and ${ }^{t} \mathrm{BDA}$ catalyzed by cobalt(II) porphyrins were revisited, and the effect of coligands was determined. While coordinating co-ligands, such as NMI and DMAP, were found to accelerate the cyclopropanation with EDA, they decelerated the cylopropanation with ${ }^{t} \mathrm{BDA}$. However, the presence of $\mathrm{MeOH}$ affected positively the outcomes of the reactions in terms of diastereo- and 
enantioselectivity. In the presence of the chiral Co-porphyrin $\mathbf{8}$ as catalyst, high yields and stereoselectivities were achieved in the cyclopropanations investigated.

\section{Acknowledgements}

This work was supported by the Fonds der Chemischen Industrie (Frankfurt, Germany).

\section{References and Notes}

[1] For the synthesis of biologically active compounds by cyclopropanation reactions, see: (a) Salaün, J. Optically active cyclopropanes. Chem. Rev. 1989, 89, 1247-1270. (b) Padwa, A.; Krumpe, K. E. Application of intramolecular carbenoid reactions in organic synthesis. Tetrahedron 1992, 48, 5385-5453. (c) Doyle, M. P.; Protopopova, M. N. New aspects of catalytic asymmetric cyclopropanation. Tetrahedron 1998, 54, 7919-7946. (d) Donaldson, W. A. Synthesis of cyclopropane containing natural products. Tetrahedron 2001, 57, 8589-8627. (e) Chen, D. Y.-K.; Pouwer, R. H.; Richard, J.-A. Recent advances in the total synthesis of cyclopropane-containing natural products. Chem. Soc. Rev. 2012, 41, 4631-4642.

[2] In general, the uses of transition metal catalysts in catalytic asymmetric cyclopropanations, see: (a) Singh, V. K.; Gupta, A. D.; Sekar, G. Catalytic enantioselective cyclopropanation of olefins using carbenoid chemistry. Synthesis 1997, 137-149. (b) Doyle, M. P.; Forbes, D. C. Recent advances in asymmetric catalytic metal carbene transformations. Chem. Rev. 1998, 98, 911-936. (c) Lebel, H.; Macoux, J.-F.; Molinaro, C.; Charette, A. B. Stereoselective cyclopropanation reactions. Chem. Rev. 2003, 103, 9771050. (d) Pellissier, H. Recent developments in asymmetric cyclopropanation. Tetrahedron 2008, 64, 7041-7095.

[3] (a) Fritschi, H.; Leutenegger, U.; Pfaltz, A. Chiral copper-semicorrin complexes as enantioselective catalysts for the cyclopropanation of olefins by diazo compounds. Angew. Chem. Int. Ed. 1986, 25, 10051006. (b) Lo, M. M.-C.; Fu, G. C. A new class of planar-chiral ligands: Synthesis of a $C_{2}$-symmetric bisazaferrocene and its application in the enantioselective $\mathrm{Cu}(\mathrm{I})$-catalyzed cyclopropanation of olefins. $J$. Am. Chem. Soc. 1998, 120, 10270-10271.

[4] (a) Doyle, M. P.; Winchester, W. R.; Hoorn, J. A. A.; Lynch, V.; Simonsen, S. H.; Ghosh, R. Dirhodium(II) tetrakis(carboxamidates) with chiral ligands. Structure and selectivity in catalytic metalcarbene transformations. J. Am. Chem. Soc. 1993, 115, 9968-9978. (b) Davies, H. M. L.; Venkataramani, C. Dirhodium tetraprolinate-catalyzed asymmetric cyclopropanations with high turnover numbers. Org. Lett. 2003, 5, 1403-1406. (c) Marcoux, D.; Azzi, S.; Charette, A. B. $\mathrm{TfNH}_{2}$ as achiral hydrogen-bond donor additive to enhance the selectivity of a transition metal catalyzed reaction. Highly enantio- and diastereoselective rhodium-catalyzed cyclopropanation of alkenes using $\alpha$-cyano diazoacetamide. J. Am. Chem. Soc. 2009, 131, 6970-6972.

[5] (a) Nishiyama, H.; Itoh, Y.; Matsumoto, H.; Park, S.-B.; Itoh, K. New chiral ruthenium bis(oxazolinyl)pyridine catalyst. Efficient asymmetric cyclopropanation of olefins with diazoacetates. $J$. Am. Chem. Soc. 1994, 116, 2223-2224. (b) Chanthamath, S.; Iwasa, S. Enantioselective cyclopropanation of a wide variety of olefins catalyzed by Ru(II)-Pheox complexes. Acc. Chem. Res. 2016, 49, 2080-2090.

[6] For cobalt-Schiff base-catalyzed asymmetric cyclopropanation, see: (a) Fukuda, T.; Katsuki, T. Co(III)salen catalyzed asymmetric cyclopropanation. Synlett 1995, 825-826. (b) Fukuda, T.; Katsuki, T. Highly enantioselective cyclopropanation of styrene derivatives using $\mathrm{Co}(\mathrm{III})$-salen complex as a catalyst. Tetrahedron 1997, 53, 7201-7208. (c) Niimi, T.; Uchida, T.; Irie, R.; Katsuki, T. Co(II)-salen-catalyzed highly cis- and enantioselective cyclopropanation. Tetrahedron Lett. 2000, 41, 3647-3651. (d) Niimi, T.; Uchida, T.; Irie, R.; Katsuki, T. Highly enantioselective cyclopropanation with Co(II)-salen complexes: Control of cis- and trans-selectivity by rational ligand-design. Adv. Synth. Catal. 2001, 343, 79-88. (e) Iwakura, I.; Ikeno, T.; Yamada, T. Proposal for the metallacycle pathway during the cyclopropanation catalyzed by cobalt-Schiff base complexes. Org. Lett. 2004, 6, 949-952. (f) Uchida, T.; Katsuki, T. $\alpha-$ Diazoacetates as carbene precursors: metallosalen-catalyzed asymmetric cyclopropanation. Synthesis 2006, 1715-1723. (g) Shitama, H.; Katsuki, T. Synthesis of metal-(pentadentate-salen) complexes: Asymmetric epoxidation with aqueous hydrogen peroxide and asymmetric cyclopropanation $\left(\mathrm{salenH}_{2}\right.$ : N,N'-bis(salicylidene)ethylene-1,2-diamine). Chem. Eur. J. 2007, 13, 4849-4858. (h) Morandi, B.; Mariampillai, B.; Carreira, E. M. Enantioselective cobalt-catalyzed preparation of trifluoromethylsubstituted cyclopropanes. Angew. Chem. Int. Ed. 2011, 50, 1101-1104. (i) White, J. D.; Shaw, S. A new 
cobalt-salen catalyst for asymmetric cyclopropanation. Synthesis of the serotonin-norepinephrine reuptake inhibitor (+)-synosutine. Org. Lett. 2014, 16, 3880-3883.

[7] For 3-oxobutylideneaminocobalt-catalyzed asymmetric cyclopropanation, see: (a) Ikeno, T.; Sato, M.; Yamada, T. Highly enantioselective cyclopropanation of styrenes with diazoacetates catalyzed by optically active $\beta$-ketoiminato cobalt(II) complexes. Chem. Lett. 1999, 1345-1346. (b) Ikeno, T.; Nishizuka, A.; Sato, M.; Yamada, T. Highly enantioselective cyclopropanation in alcoholic and aqueous solvents catalyzed by optically active $\beta$-ketoiminato cobalt(II) complex. Synlett 2001, 406-408. (c) Ikeno, T.; Iwakura, I.; Yamada, T. Cobalt-carbene complex with single-bond character: Intermediate for the cobalt complex-catalyzed cyclopropanation. J. Am. Chem. Soc. 2002, 124, 15152-15153.

[8] Callot, H. J.; Piechocki, C. Cyclopropanation using rhodium (III) porphyrins: Large cis vs trans selectivity. Tetrahedron Lett. 1980, 21, 3489-3492.

[9] (a) O’Malley, S.; Kodadek, T. Asymmetric cyclopropanation of alkenes catalyzed by a "chiral wall" prophyrin. Tetrahedron Lett. 1991, 32, 2445-2448. (b) Maxwell, J. L.; O’Malley, S.; Brown, K. C.; Kodadek, T. Shape-selective and asymmetric cyclopropanation of alkenes catalyzed by rhodium porphyrins. Organometallics 1992, 11, 645-652. (c) O’Malley, S.; Kodadek, T. Asymmetric cyclopropanation of alkenes catalyzed by a rhodium chiral fortress porphyrin. Organometallics 1992, 11, 2299-2302.

[10] For Ir(III) porphyrin-catalyzed cyclopropanation, see: Anding, B. J.; Ellern, A.; Woo, L. K. Olefin cyclopropanation catalyzed by iridium(III) porphyrin complexes. Organometallics 2012, 31, 3628-3635.

[11] For Os(III) porphyrin-catalyzed cyclopropanation, see: Che, C.-H.; Huang, J.-S. Ruthenium and osmium porphyrin carbene complexes: Synthesis, structure, and connection to the metal-mediated cyclopropanation of alkenes. Coord. Chem. Rev. 2002, 231, 151-164.

[12] For Fe(II) porphyrin-catalyzed non-asymmetric cyclopropanation, see: (a) Hamaker, C. G.; Mirafzal, G. A.; Woo, L. K. Catalytic cyclopropanation with iron(II) complexes. Organometallics 2001, 20, 5171 5176. (b) Morandi, B.; Carreira, E. M. Iron-catalyzed cyclopropanation with trifluoroethylamine hydrochloride and olefins in aqueous media: In situ generation of trifluoromethyl diazomethan. Angew. Chem. Int. Ed. 2010, 49, 938-941.

[13] For enantioselective cyclopropanation catalyzed by chiral Fe(II) porphyrins, see: (a) Du, G.; Andrioletti, B.; Rose, E.; Woo, L. K. Asymmetric cyclopropanation of styrene catalyzed by chiral macrocyclic iron(II) complexes. Organometallics 2002, 21, 4490-4495. (b) Lai, T.-S.; Chan, F.-Y.; So, P.-K.; Ma, D.L.; Wong, K.-Y.; Che, C.-M. Alkene cyclopropanation catalyzed by Halterman iron porphyrin: Participation of organic bases as axial ligands. Dalton Trans. 2006, 4845-4851. (c) Intrieri, D.; Le Gac, S.; Caselli, A.; Rose, E.; Boitrel, B.; Gallo, E. Highly diastereoselective cyclopropanation of $\alpha-$ methylstyrene catalysed by a $C_{2}$-symmetrical chiral iron porphyrin complex. Chem. Commun. 2014, 50, 1811-1813. (d) Rioz-Martínez, A.; Oelerich, J.; Ségaud, N.; Roelfes, G. DNA-accelerated catalysis of carbene-transfer reactions by a DNA/cationic iron porphyrin hybrid. Angew. Chem. Int. Ed. 2016, 55, 14136-14140.

[14] For Ru(II) porphyrin-catalyzed cyclopropanation of olefins, see: (a) Galardon, E.; Le Maux, P.; Simonneaux, G. Cyclopropanation of alkenes with ethyl diazoacetate catalysed by ruthenium porphyrin complexes. Chem. Commun. 1997, 927-928. (b) Lo, W.-C.; Che, C.-M.; Cheng, K.-F.; Mak, T. C. W. Catalytic and asymmetric cyclopropanation of styrenes catalysed by ruthenium porphyrin and porphycene complexes. Chem.Commun. 1997, 1205-1206. (c) Frauenkron, M.; Berkessel, A. A novel chiral ruthenium porphyrin as highly efficient and selective catalyst for asymmetric cyclopropanations. Tetrahedron Lett. 1997, 38, 7175-7176. (d) Galardon, E.; Roué, S.; Le Maux, P.; Simonneaux, G. Asymmetric cyclopropanation of alkenes and diazocarbonyl insertion into S-H bonds catalyzed by a chiral porphyrin Ru(II) complex. Tetrahedron Lett. 1998, 39, 2333-2334. (e) Gross, Z.; Galili, N.; Simkhovich, L. Metalloporphyrin catalyzed asymmetric cyclopropanation of olefins. Tetrahedron Lett. 1999, 40, 1571-1574. (f) Che, C.-M. ; Huang, J.-S.; Lee, F.-W.; Lai, T.-S.; Kwong, H.-L.; Teng, P.-F.; Lee, W.-S.; Lo, W.-C.; Zhou, Z.-Y. Asymmetric inter- and intramolecular cyclopropanation of alkenes catalyzed by chiral ruthenium porphyrins. Synthesis and crystal structure of a chiral metalloporphyrin carbene complex. J. Am. Chem. Soc. 2001, 123, 4119-4129. (g) Simonneaux, G.; Le Maux, P. Optically active ruthenium porphyrins: Chiral recognition and asymmetric catalysis. Coor. Chem. Rev. 2002, 228, 43-60. (h) Berkessel, A.; Kaiser, P.; Lex, J. Electronically tuned chiral ruthenium porphyrins: Extremely stable and selective catalysts for asymmetric epoxidation and cyclopropanation. Chem. Eur. J. 2003, 9, 4746-4756. (i) Ferrand, Y.; Le Maux, P.; Simonneaux, G. Highly enantioselective synthesis of cyclopropylphosphonates catalyzed by chiral ruthenium porphyrins. Org. Lett. 2004, 6, 3211-3214. (j) 
Zhou, C.-Y.; Huang, J.-S.; Che, C.-M. Ruthenium-porphyrin-catalyzed carbenoid transfer reactions. Synlett 2010, 2681-2700.

[15] For stoichiometric reactions of ethyl diazoacetate with cobalt(II) porphyrin complexes, see: (a) Johnson, A. W.; Ward, D.; Batten, P.; Hamilton, A. L.; Shelton, G.; Elson, C. M. Condensation of ethyl diazoacetate with cobalt porphyrins. J. Chem. Soc., Perkin Trans.1 1975, 2076-2085. (b) Penoni, A.; Wanke, R.; Tollari, S.; Gallo, E.; Musella, D.; Ragaini, F.; Demartin, F.; Cenini, S. Cyclopropanation of olefins with diazoalkanes, catalyzed by $\mathrm{Co}^{\mathrm{II}}$ (porphyrin) complexes - A synthetic and mechanistic investigation and the molecular structure of $\mathrm{Co}$ (III $(\mathrm{TPP})\left(\mathrm{CH}_{2} \mathrm{CO}_{2} \mathrm{Et}\right)$ (TPP $=$ dianion of mesotetraphenylporphyrin). Eur. J. Inorg. Chem. 2003, 1452-1460. (c) Iwakura, I.; Tanaka, H.; Ikeno, T.; Yamada, T. FT-IR and theoretical analysis of the characteristic bonding properties in the multiplet metal porphyrin carbene complexes. Chem. Lett. 2004, 33, 140-141.

[16] Asymmetric cyclopropanation of olefins with diazo esters catalyzed by cobalt(II) porphyrins, see: (a) Huang, L.; Chen, Y.; Gao, G.-Y.; Zhang, X. P. Diastereoselective and enantioselective cyclopropanation of alkenes catalyzed by cobalt porphyrins. J. Org. Chem. 2003, 68, 8179-8184. (b) Chen, Y.; Zhang, X. P. Vitamin $\mathrm{B}_{12}$ derivatives as natural asymmetric catalysts: Enantioselective cyclopropanation of alkenes. $J$. Org. Chem. 2004, 69, 2431-2435. (c) Chen, Y.; Fields, K. B.; Zhang, X. P. Bromoporphyrins as versatile synthons for modular construction of chiral porphyrins: Cobalt-catalyzed highly enantioselective and diastereoselective cyclopropanation. J. Am. Chem. Soc. 2004, 126, 14718-14719. (d) Chen, Y.; Gao, G.Y.; Zhang, X. P. Palladium-mediated synthesis of novel meso-chiral porphyrins: Cobalt-catalyzed cyclopropanation. Tetrahedron Lett. 2005, 46, 4965-4969. (e) Chen, Y.; Ruppel, J. V.; Zhang, X. P. Cobalt-catalyzed asymmetric cyclopropanation of electron-deficient olefins. J. Am. Chem. Soc. 2007, 129, 12074-12075. (f) Fantauzzi, S.; Gallo, E.; Rose, E.; Raoul, N.; Caselli, A.; Issa, S.; Ragaini, F.; Cenini, S. Asymmetric cyclopropanation of olefins catalyzed by chiral cobalt(II)-binaphthyl porphyrins. Organometallics 2008, 27, 6143-6151. (g) Fields, K. B.; Engle, J. T.; Sripothongnak, S.; Kim, C.; Zhang, X. P.; Ziegler, C. J. Cobalt carbaporphyrin-catalyzed cyclopropanation. Chem. Commun. 2011, 47, 749751. (h) Xu, X.; Lu, H.; Ruppel, J. V.; Cui, X.; de Mesa, S. L.; Wojtas, L.; Zhang, X. P. Highly asymmetric intramolecular cyclopropanation of acceptor-substituted diazoacetates by Co(II)-based metalloradical catalysis: Iterative approach for development of new-generation catalysts. J. Am. Chem. Soc. 2011, 133, 15292-15295. (i) Xu, X.; Zhu, S.; Cui, X.; Wojtas, L.; Zhang, X. P. Cobalt(II)-catalyzed asymmetric olefin cyclopropanation with $\alpha$-ketodiazoacetates. Angew. Chem. Int. Ed. 2013, 52, $11857-$ 11861.

[17] Dzik, W. I.; Xu, X.; Zhang, X. P.; Reek, J. N. H.; de Bruin, B. 'Carbene radicals' in Co II (por)-catalyzed olefin cyclopropanation. J. Am. Chem. Soc. 2010, 132, 10891-10902.

[18] (a) Intrieri, D.; Caselli, A.; Gallo, E. Cyclopropanation reactions mediated by group 9 metal porphyrin complexes. Eur. J. Inorg. Chem. 2011, 5071-5081. (b) Intrieri, D.; Maria, D. M.; Gallo, E. The ligand influence in stereoselective carbene transfer reactions promoted by chiral metal porphyrin catalysts. Dalton Trans. 2016, 45, 15746-15761.

[19] Zhu, S.; Ruppel, J. V.; Lu, H.; Wojtas, L.; Zhang, X. P. Cobalt-catalyzed asymmetric cyclopropanation with diazosulfones: Rigidification and polarization of ligand chiral environment via hydrogen bonding and cyclization. J. Am. Chem. Soc. 2008, 130, 5042-5043.

[20] Zhu, S.; Perman, J. A.; Zhang, X. P. Acceptor/acceptor-substituted diazo reagents for carbene transfers: Cobalt-catalyzed asymmetric Z-cyclopropanation of alkenes with $\alpha$-nitrodiazoacetates. Angew. Chem. Int. Ed. 2008, 47, 8460-8463.

[21] Ruppel, J. V.; Gauthier, T. J.; Snyder, N. L.; Perman, J. A.; Zhang X. P. Asymmetric Co(II)-catalyzed cyclopropanation with succinimidyl diazoacetate: General synthesis of chiral cyclopropyl carboxamides. Org. Lett. 2009, 11, 2273-2276.

[22] Zhu, S.; Xu, X.; Perman, J. A.; Zhang, X. P. A general and efficient cobalt(II)-based catalytic system for highly stereoselective cyclopropanation of alkenes with $\alpha$-cyanodiazoacetates. J. Am. Chem. Soc. 2010 , $132,12796-12799$.

[23] Cui, X.; Xu, X.; Lu, H.; Zhu, S. Wojtas, L.; Zhang, X. P. Enantioselective cyclopropenation of alkynes with acceptor/acceptor-substituted diazo reagents via $\mathrm{Co}$ (II)-based metalloradical catalysis. J. Am. Chem. Soc. 2011, 133, 3304-3307.

[24] (a) Berkessel, A.; Frauenkron, M. Catalytic asymmetric epoxidation with a chiral ruthenium porphyrin and N-oxides J. Chem. Soc., Perkin Trans. 1 1997, 2265-2266. (b) Berkessel, A.; Ertürk, E.; Laporte, C. Chiral chromium(III) porphyrins as highly enantioselective catalysts for hetero-Diels-Alder reactions 
between aldehydes and dienes. Adv. Synth. Catal 2006, 348, 223-228. (c) Berkessel, A.; Ertürk, E.; Kaiser, P.; Klein, A.; Kowalczyk, R. M.; Sarkar, B. On the redox states of ruthenium porphyrin oxidation catalysts. Dalton Trans. 2007, 3427-3434.

[25] Li, F.; Yang, K.; Tyhonas, J. S.; MacCrum, K. A.; Lindsey, J. S. Beneficial effects of salts on an acidcatalyzed condensation leading to porphyrin formation. Tetrahedron 1997, 53, 12339-12360.

[26] Polam, J. R.; Shokhireva, T. Kh.; Raffii, K.; Simonis, U.; Walker, F. A. Rates of axial ligand rotation in diamagnetic $\mathrm{d}^{6} \mathrm{Co}$ (III) and $\mathrm{Fe}(\mathrm{II})$ porphyrinates. Inorg. Chim. Acta 1997, 263, 109-117.

[27] (a) Halterman, R. L.; Jan, S.-T. Catalytic asymmetric epoxidation of unfunctionalized alkenes using the first D4-symmetric metallotetraphenylporphyrin. J. Org. Chem. 1991, 56, 5253-5254. (b) Halterman, R. L.; Jan, S.-T.; Nimmons, H. L.; Standlee, D. J.; Khan, M. A. Synthesis and catalytic reactivity of D4symmetric dinorbornabenzene-derived metallotetraarylporphyrins. Tetrahedron 1997, 53, 11257-11276.

[28] Searle, N. E. Ethyl diazoacetate. Org. Synth. 1956, 36, 25-27.

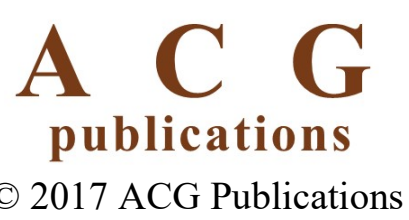

